\title{
Relations between respiratory symptoms and sickness among workers in the animal feed industry
}

\author{
Wendel K Post, Alex Burdorf, Ton G Bruggeling
}

\begin{abstract}
Objective-The survey aimed at studying the associations between prevalent respiratory symptoms in an occupational population and sickness absence due to respiratory disorders.

Methods-A cross sectional survey among male workers in an animal feed mill was conducted. A total of 303 production workers and 102 office clerks completed a questionnaire on respiratory complaints, smoking habits, and occupational history. The questionnaire was used to identify workers with respiratory symptoms in the past 12 months. During this period all spells of sickness absence were recorded. Causes of sickness were classified in broad categories encompassing respiratory symptoms, influenza, musculoskeletal disorders, and others.
\end{abstract}

Results-Logistic regression analysis showed that workers with respiratory complaints experienced a higher sickness absence than those without respiratory complaints. Adjusted for age and smoking the odds ratio (OR) for sickness prevalence was 1.9 among office clerks and 2.6 among blue collar workers. Smoking increased the risk on sickness absence with ORs of $2 \cdot 4$ and $1 \cdot 6$, respectively. When restricting the analysis to sickness due to respiratory complaints, subjects with respiratory complaints had significantly higher risks for absence prevalence and absence rate than those without respiratory complaints. There were no differences in sickness absence between workers with asthma like complaints and those with chronic bronchitis like complaints.

Conclusion-The clear associations between respiratory complaints and prevalence and rate of respiratory sickness absence indicate that workers with respiratory complaints are at risk of temporary disability and, thus, may experience a reduced ability to cope with routine activities at work.

(Occup Environ Med 1994;51:440-446)

Asthma, chronic bronchitis, and emphysema are significant causes of morbidity and mortality in most affluent societies. ${ }^{1-4}$ Although the precise definitions of the particular diseases have been vigorously debated for many years, these chronic non-specific lung diseases share common features such as shortness of breath, wheezing, chronic cough, and chronic phlegm production. ${ }^{5}$ Several surveys in occupational populations have shown that various agents in the working environment play a part in the aetiological mechanisms underlying these respiratory symptoms. ${ }^{467}$

Given the abundant number of publications on occupational asthma and chronic obstructive pulmonary disease it is surprising that the ability of workers with respiratory symptoms to cope with routine activities at work has been studied only occasionally. Sickness absence is an important measure of ill health and often a prominent source of information to act on in occupational health care. Consequently, it may be an interesting measure of morbidity to evaluate the influence of respiratory symptoms on work capacity. Sickness absence is influenced by social and psychological factors as well as illness state and work requirements. ${ }^{8}$ These factors intermingle in determining the subject's possibility to maintain a normal performance at work.

A few studies have documented that sickness absence is increased among workers with respiratory symptoms. An early survey among electrical workers showed that chronic cough, diminished forced expiratory volume, and chronic phlegm production were predictive of days of sickness absence due to respiratory illness. ${ }^{9}$ This finding was confirmed in a study among workers of a fertiliser factory, which showed that subjects with persistent chronic cough and phlegm production were absent because of chest diseases more often and longer than workers without these symptoms. ${ }^{10}$ One study added to the list of possible predictors of days of respiratory sickness absence, pronounced shortness of breath, and chronic wheeze. ${ }^{11}$

These studies have presented evidence that sickness absence may be a useful measure to evaluate the consequences of having respiratory symptoms at work. Moreover, knowledge of the causes of sickness absence could possibly contribute to secondary prevention by identifying subjects with respiratory symptoms and subsequent illness at a sufficiently early stage to prevent permanent disability. ${ }^{12}$

The primary aim of this survey was to study determinants of sickness absence due to respiratory symptoms. Factors under study included the presence of respiratory symptoms, smoking, age, amount of exposure, and other job characteristics. A secondary goal was to evaluate the usefulness of routinely
Accepted for publication 5 April 1994 
collected data on sickness absence in establishing prevention programmes for workers with respiratory symptoms.

\section{Subjects and methods}

A respiratory health survey was conducted among male workers in an animal feed mill in The Netherlands. Subjects employed in their present job for at least 12 months were invited to participate in the study. Female workers were excluded because of too small numbers, especially in the blue collar jobs. Workers who had taken early retirement as well as workers who became permanently disabled during the study period were also excluded. None of the second group became disabled due to respiratory diseases. The population consisted of the entire workforce of the animal feed mill, comprising blue collar workers at different production departments, maintenance personnel, and office clerks. Production workers and maintenance personnel were regularly exposed to organic dusts, such as various grains and cassava, which may cause respiratory symptoms. ${ }^{13}$ Maintenance workers were also exposed to other hazardous agents like soldering and welding fumes, oils, and solvents. ${ }^{6}$ The office clerks were used as controls as occupational exposure to inhalable agents was almost zero in this group.

Information on respiratory symptoms, smoking habits, and work history was gathered from a self administered questionnaire. The questions on respiratory symptoms resembled those from a standardised European questionnaire. ${ }^{14} 15$ Questions asked about complaints of chronic cough, chronic sputum secretion, wheezing, shortness of breath, and attacks of chest tightness (asthma). Subjects who reported at least one of these symptoms were classified as prevalent cases of respiratory symptoms. Asthma like symptoms were derived from questions on wheezing for at least one week in the past two years, shortness of breath at any time in the past two years, or chest tightness in the morning at any time in the past two years. Chronic bronchitis like symptoms were defined as chronic cough or chronic phlegm for at least three months a year in the previous two consecutive years. The remaining workers with other respiratory complaints or a combination of asthma like and bronchitis like complaints were classified as miscellaneous. For subjects with one or more respiratory symptoms, additional information on medical consumption and frequency and duration of their symptoms in the six months before presenting the questionnaire was required. Workers with respiratory complaints who consulted their general practitioner or a specialist, took medication to alleviate their symptoms, or reported to have had symptoms almost daily during the past six months were considered to be cases with severe respiratory complaints.

The questionnaire also categorised workers into non-smokers (never smoked), current smokers (currently smoking cigarettes, cigars, or pipes), and former smokers (formerly smoked regularly but stopped smoking for at least one year before the study). Those who stopped smoking less than one year before the study were classified as current smokers. The section covering occupational history collected information on job titles and duration of employment in the current and previous companies. Employment in the current job was used as a proxy of duration of exposure to organic dusts. Previous jobs were assigned the presence or absence of exposure to allergens.

The company register of sickness absence was used to retrieve sickness absence records covering the year before giving the questionnaire. Due to changes in the register a longer period for collecting retrospectively valid data was not feasible. This register is part of the company's insurance system. If a worker falls ill, he is obliged to report his absence to the administration office. Subsequently, these workers are visited by a trained layman who reports on complaints and causes of the sickness to the register. Although the company policy is that absent workers should be visited on the first day of absence, in practice absences of two days or less usually go without a diagnosis of the cause. Every week the trained layman and the occupational physician discuss the medical background of absent workers. Workers who have been absent for four weeks or those with severe problems are invited to the medical service on site. The occupational physician examines these workers and documents his diagnoses in medical files. The company register of sickness absence comprises frequency and duration of sickness absences and diagnoses according to the International Classification of Diseases. It provides the following outcomes of sickness absence for each worker: (1) absence rate; the total number of calendar days of sickness absence in the past 12 months, expressed as a percentage of 365 days; (2) absence frequency; the total number of periods of sickness absence in the past 12 months; (3) absence duration: the mean number of calendar days of periods of sickness absence in the past 12 months; (4) absence prevalence: the percentage of workers with at least one period of sickness absence in the past 12 months.

The layman's reports and the physician's diagnoses were used to categorise the cause of sickness absence into six groups (by one of the authors, TB). The categories distinguished were respiratory symptoms, influenza, back pain, other musculoskeletal disorders, other diseases, and reasons unknown. The group of respiratory symptoms included the respiratory symptoms mentioned in the questionnaire, cold, pneumonia, and sore throat.

Categorical data were analysed by MantelHaenszel $\chi^{2}$ tests. The hypothesis that the means of normally distributed variables differ significantly was tested with two tailed $t$ tests. Continuous variables not normally distributed are presented as medians and ranges and were analysed by the Mann-Whitney $U$ test. The measure of association between risk factors and respiratory symptoms was the odds ratio (OR). Unconditional logistic regression 
Table 1 Characteristics of office clerks and blue collar workers in an animal feed company, stratified by the presence of at least one respiratory symptom

\begin{tabular}{|c|c|c|c|c|c|c|}
\hline & \multicolumn{3}{|l|}{ Office clerks } & \multicolumn{3}{|c|}{ Blue collar workers } \\
\hline & Total & No symptoms & $\geqslant 1$ symptom & Total & No symptoms & $\geqslant 1$ symptom \\
\hline $\begin{array}{l}\text { No } \\
\text { Age }(y)(\text { mean }(\mathrm{SD}))^{\star 1} 2 \\
\text { Non-smokers }(\mathrm{No}(\%)) \dagger^{12} \\
\text { Ex-smokers (No }(\%)) \dagger^{12} \\
\text { Smokers (No }(\%)) \dagger^{12} \\
\text { Years smoked (mean (SD)) })^{\star 12} \\
\text { Pack-years (mean (SD) })^{\star 2} \\
\text { Working years (mean (SD)) })^{\star 1}\end{array}$ & $\begin{array}{l}102 \\
38 \cdot 3(9 \cdot 2) \\
46(45) \\
26(26) \\
30(29) \\
23 \cdot 7(11 \cdot 3) \\
19 \cdot 8(13 \cdot 3) \\
13 \cdot 2(9 \cdot 4)\end{array}$ & $\begin{array}{l}82 \\
38 \cdot 9(9 \cdot 3) \\
38(46) \\
23(28) \\
21(25) \\
24 \cdot 1(11 \cdot 4) \\
19 \cdot 6(13 \cdot 3) \\
13 \cdot 7(9 \cdot 5)\end{array}$ & $\begin{array}{l}20 \\
36 \cdot 1(8 \cdot 7) \\
8(40) \\
3(15) \\
9(45) \\
22 \cdot 7(12 \cdot 0) \\
20 \cdot 5(13 \cdot 9) \\
11 \cdot 2(9 \cdot 2)\end{array}$ & $\begin{array}{l}303 \\
42 \cdot 3(9 \cdot 6) \\
56(18) \\
109(36) \\
138(46) \\
22 \cdot 1(11 \cdot 3) \\
16 \cdot 7(13 \cdot 7) \\
16 \cdot 8(9 \cdot 2)\end{array}$ & $\begin{array}{l}242 \\
41 \cdot 5(9 \cdot 7) \\
52(21) \\
94(39) \\
96(40) \\
20 \cdot 0(11 \cdot 3) \\
13 \cdot 6(10 \cdot 9) \\
16 \cdot 6(9 \cdot 4)\end{array}$ & $\begin{array}{l}61 \\
45 \cdot 1(8 \cdot 3) \\
4(7) \\
15(25) \\
42(69) \\
27 \cdot 0(9 \cdot 9) \\
23 \cdot 8(16 \cdot 7) \\
17 \cdot 4(8 \cdot 2)\end{array}$ \\
\hline
\end{tabular}

$\star \mathrm{p}<0.05$ ( \pm test) $;$ tp $<0.05\left(x^{2}\right.$ test)

ISignificant difference between office clerks and blue collar workers;

${ }^{2}$ Significant difference between blue collar workers with and without respiratory symptoms.

analysis was performed to determine the influence of age, smoking habits, and work history on respiratory complaints. Similar analyses were employed to study the effect of age, smoking habits, work history, and respiratory complaints on total sickness absence and sickness absence due to respiratory symptoms. These analyses were restricted to absence prevalence and absence rate as these variables were most stable in the population under study. Thus the absence rate as an overall measure of absence was preferred to separate analyses of frequency and duration. Because the distributions of rates of sickness absence were highly skewed, the absence rates of all causes and of respiratory symptoms were dichotomised at $2 \cdot 4 \%$ and $1.4 \%$ among office workers and at $7 \cdot 6 \%$ and $3.1 \%$ among blue collar workers. By this procedure subjects with a high absence rate (the highest quartile) could be compared with subjects with a low absence rate.

\section{Results}

Four hundred and thirteen (80\%) workers completed the questionnaire. Data on smoking habits were incomplete for six production workers and two office clerks, resulting in a useful response of $303(76 \%)$ blue collar workers and $102(86 \%)$ office clerks. Of the workers who failed to return the.questionnaire sickness absence records were traced to employ a non-response analysis. In both groups responders and non-responders had a similar prevalence of absence. Among the

Table 2 Respiratory symptoms among office clerks and blue collar workers with chronic non-specific lung disease

\begin{tabular}{lll}
\hline & $\begin{array}{l}\text { Office clerks } \\
(n=20) \\
n(\%)\end{array}$ & $\begin{array}{l}\text { Blue collar workers } \\
\left(\begin{array}{l}n=61) \\
n(\%)\end{array}\right.\end{array}$ \\
\hline Chronic cough & $9(45)$ & $28(45)$ \\
Chronic sputum secretion & $7(35)$ & $23(37)$ \\
Shortness of breath & $2(10)$ & $17(27)$ \\
Ever wheezing & $9(45)$ & $21(55)$ \\
Wheezing for more than 1 week & $2(10)$ & $15(24)$ \\
Chest tightness (asthma) & $5(25)$ & $19(31)$ \\
Asthma like symptoms & $4(20)$ & $18(30)$ \\
Chronic bronchitis like & $7(35)$ & $24(39)$ \\
symptoms & $9(45)$ & $8(13)$ \\
Miscellaneous & $9(45)$ &
\end{tabular}

${ }^{\star} \mathrm{p}<0.05\left(x^{2}\right.$ test). office clerks the non-responders showed a slightly higher frequency $(1.9 v 1.5)$ and higher mean duration (4.4 $v 3.0)$ of absence and thus a higher absence rate $(2.9 v 1.8)$ than the responders. Non-responding blue collar workers were sick more often $(2.5 v$ $2 \cdot 0)$ and consequently had a higher absence rate $(7 \cdot 3 v 6 \cdot 2)$. The best part of their increased absence rate could be explained by differences in sickness absence due to influenza.

Table 1 gives some characteristics of both occupational groups, stratified by the presence of at least one respiratory symptom (defined as the presence of chronic non-specific lung diseases). The blue collar workers were, on average, older and had been employed longer at the animal feed mill than the office clerks. Also the smoking habits between the two groups differed significantly; the blue collar workers were more often current smokers or former smokers. On average, ex-smokers stopped smoking almost 12 years before the study. In both groups stratification by the occurrence of respiratory symptoms showed a positive association with current smoking. Blue collar workers with respiratory symptoms also showed a considerable increase in the number of years of smoking and the total amount of cigarettes smoked (expressed as pack-years $=$ number of packs of 20 cigarettes a day multiplied by the number of years smoked) when compared with blue collar workers without these complaints. Among office clerks, these differences were not found between subjects with and without respiratory symptoms.

The prevalence of respiratory symptoms was $20 \%$ in both occupational groups. Table 2 presents the nature of the respiratory symptoms reported by the workers. For most respiratory complaints no significant difference was found between the office clerks and the blue collar workers. The prevalence of wheezing for at least one week in the past two years was higher among the blue collar workers than the office clerks; this difference approached significance $(34 \%$ v $10 \% ; \mathrm{p}=$ 0.09 ). Classifying the respiratory symptoms into asthma like symptoms and chronic bronchitis like symptoms showed similar prevalences in both occupational groups. Among office clerks and blue collar workers $15 \%$ and 
Table 3 Total and cause specific sickness absence during 12 months among office clerks and blue collar workers in an animal feed company, stratified by the presence of at least one respiratory symptom

\begin{tabular}{|c|c|c|c|c|}
\hline & \multicolumn{2}{|c|}{ Office clerks $(n=102)$} & \multicolumn{2}{|c|}{ Blue collar workers $(n=303)$} \\
\hline & $\begin{array}{l}\text { No } \\
\text { symptoms } \\
(n=82)\end{array}$ & $\begin{array}{l}\text { Respiratory } \\
\text { symptoms } \\
(n=20)\end{array}$ & $\begin{array}{l}\text { No } \\
\text { symptoms } \\
(n=242)\end{array}$ & $\begin{array}{l}\text { Respiratory } \\
\text { symptoms } \\
(n=61)\end{array}$ \\
\hline \multicolumn{5}{|l|}{ Total sickness absence: } \\
\hline Absence prevalence & $58(71)$ & $17(85)$ & $193(80)$ & $56(92)^{\star}$ \\
\hline Absence frequency & $1 \cdot 3$ & $2 \cdot 5$ & 1.9 & $2 \cdot 5$ \\
\hline Absence duration (days) & $3 \cdot 1$ & $2 \cdot 6$ & $8 \cdot 7$ & $16 \cdot 1$ \\
\hline Absence rate (\%) & $1 \cdot 7$ & $2 \cdot 0$ & $5 \cdot 3$ & $10 \cdot 1$ \\
\hline \multicolumn{5}{|c|}{ Sickness absence due to respiratory disorders: } \\
\hline Absence prevalence & $11(13)$ & $7(35)^{\star}$ & $29(12)$ & $14(23)^{\star}$ \\
\hline Absence frequency & $0 \cdot 1$ & $0 \cdot 6$ & 0.1 & 0.3 \\
\hline Absence duration (days) & 0.6 & $1 \cdot 3$ & 0.2 & $4 \cdot 4$ \\
\hline Absence rate $(\%)$ & $0 \cdot 2$ & $0 \cdot 6$ & $0 \cdot 7$ & $1 \cdot 3$ \\
\hline \multicolumn{5}{|c|}{ Sickness absence due to influenza: } \\
\hline Absence prevalence & $37(45)$ & $13(65)$ & $88(36)$ & $30(49)$ \\
\hline Absence frequency & 0.6 & $1 \cdot 2$ & 0.5 & 0.7 \\
\hline Absence duration (days) & $1 \cdot 7$ & $1 \cdot 7$ & $2 \cdot 3$ & $3 \cdot 6$ \\
\hline Absence rate $(\%)$ & 0.6 & $0 \cdot 8$ & $0 \cdot 8$ & $1 \cdot 6$ \\
\hline
\end{tabular}

${ }^{\star} \mathrm{p}<0.05\left(\chi^{2}\right.$ test $)$. Numbers in parentheses are percentages.

$30 \%$ respectively reported a combination of respiratory complaints associated with either asthma or chronic bronchitis. Among the office clerks nine (45\%) had experienced respiratory symptoms before their first employment ever, against only eight $(13 \%)$ blue collar workers $\left(x^{2}\right.$ test, $\left.p<0.05\right)$. For 14 of 17 subjects the symptoms described fitted the presence of asthma at an early age. About half of the subjects with respiratory symptoms reported a gradually worsening of their symptoms in the past few years.

The natural history and severity of respiratory complaints in the past six months showed no pronounced differences between office clerks and blue collar workers. About $78 \%$ (63) of the subjects had experienced respiratory symptoms in the past six months; of those $27 \%$ had experienced one spell, $30 \%$ had experienced two to 10 spells, and the remaining $43 \%$ had experienced at least 10 spells. The total duration of respiratory symptoms within the past six months indicated that $51 \%$ had symptoms for seven days or less, $5 \%$ had symptoms lasting eight to 14 days, and $44 \%$ reported more than 14 days to almost daily respiratory symptoms. In the past six months, the number of workers taking medicine was high; $37 \%$ had visited their general practitioner or lung specialist, and $30 \%$ reported taking medications for their respiratory symptoms.

Table 3 shows the information retrieved from the register of sickness absence. Both among the office clerks and the blue collar workers the percentage of workers without any sickness absence was small, $26 \%$ and $18 \%$ respectively. During the 12 months of study, the office clerks recorded 158 periods of absence covering 648 days. The corresponding figures for the blue collar workers were 614 periods of absence covering 7093 days. About a quarter of the periods of sickness absence could not be attributed to a specific cause. This was predominantly due to short term sickness absence. Hence, the absence rate contained $5 \cdot 7 \%$ days with sickness absence of unknown cause. The office workers had a significantly lower absence rate, primarily the result of shorter periods of absence. Respiratory symptoms and influenza accounted for $52 \%$ of the days lost among the office workers and for $21 \%$ among the blue collar workers $\left(\chi^{2}\right.$ test, $\left.\mathrm{p}<0.05\right)$. For the blue collar workers musculoskeletal disorders were the principal cause of sickness absence with a contribution of $30 \%$ to the total sickness absence. When stratified by presence of respiratory symptoms the sickness absence showed a similar pattern in both groups. Among subjects with respiratory symptoms there were higher absence prevalences and absence rates caused by any sickness, by respiratory symptoms, and by influenza. In the blue collar groups, among those with respiratory symptoms a twofold absence rate was found, independent of the cause of sickness, as well as a much higher absence duration, most pronounced for respiratory sickness.

The logistic regression analysis of risk factors for the presence of respiratory complaints showed opposite trends for age in both groups. Among blue collar workers the risk increased with age, whereas the youngest office clerks had the highest risk. When including duration of employment instead of age in the logistic models, similar trends as those for age were found. Occupational history was not associated with the prevalence of respiratory symptoms. Respiratory symptoms were more prevalent among current smokers, with ORs of $3.0(95 \%$ CI $0.9-10.4)$ for office clerks and $5 \cdot 2(95 \% \mathrm{CI} 1 \cdot 8-15 \cdot 7)$ for blue collar workers. Ex-smoking was not of statistically significant importance.

Tables 4 and 5 describe the influence of

Table 4 Influence of age, smoking habit, and respiratory complaints on absence prevalence, absence prevalence due to respiratory symptoms, absence rate, and absence rate due to respiratory symptoms among office clerks

\begin{tabular}{|c|c|c|c|c|c|}
\hline Risk factor & $\begin{array}{l}\text { No of } \\
\text { workers }\end{array}$ & $\begin{array}{l}\text { Absence prevalence } \\
\text { OR }(95 \% C I)\end{array}$ & $\begin{array}{l}\text { Absence prevalence due to } \\
\text { respiratory symptoms } \\
\text { OR }(95 \%-C I)\end{array}$ & $\begin{array}{l}\text { Absence rate† } \\
\text { OR }(95 \%-C I)\end{array}$ & $\begin{array}{l}\text { Absence rate } \ddagger \text { due to } \\
\text { respiratory symptoms } \\
\text { OR }(95 \%-C I)\end{array}$ \\
\hline \multicolumn{6}{|l|}{ Age (y): } \\
\hline $\begin{array}{l}21-35 \\
36-50 \\
51-65\end{array}$ & $\begin{array}{l}46 \\
43 \\
13\end{array}$ & $\begin{array}{l}1.00 \\
0.99(0.32-3.11) \\
0.21^{*}(0.05-0.94)\end{array}$ & $\begin{array}{l}1.00 \\
0.71(0.19-2.64) \\
0.99(0.15-6.44)\end{array}$ & $\begin{array}{l}1.00 \\
0.48(0 \cdot 15-1.54) \\
0.89(0 \cdot 19-4 \cdot 20)\end{array}$ & $\begin{array}{l}1.00 \\
1.58(0.19-13.40) \\
4.55(0.39-53.73)\end{array}$ \\
\hline \multicolumn{6}{|l|}{ Smoking habit: } \\
\hline Non-smoker & 46 & 1.00 & 1.00 & $1 \cdot 00$ & 1.00 \\
\hline Ex-smoker & 26 & $0.74(0.22-2.48)$ & $1.01(0 \cdot 24-4 \cdot 20)$ & $0.96(0 \cdot 22-4.09)$ & $2 \cdot 26(0 \cdot 26-19 \cdot 69)$ \\
\hline Smoker & 30 & $2.36(0.62-8.97)$ & $0.32(0.07-1.53)$ & $2.59(0.81-8.30)$ & $0.77(0.07-8.11)$ \\
\hline \multicolumn{6}{|l|}{ Respiratory complaints: } \\
\hline $\begin{array}{l}\text { No symptoms } \\
\geqslant 1 \text { symptom }\end{array}$ & $\begin{array}{l}82 \\
20\end{array}$ & $\begin{array}{l}1.00 \\
1.85(0.47-7.28)\end{array}$ & $\begin{array}{l}1 \cdot 00 \\
4 \cdot 40^{\star}(1 \cdot 31-14.93)\end{array}$ & $\begin{array}{l}1 \cdot 00 \\
3 \cdot 41^{\star}(1 \cdot 18-10 \cdot 14)\end{array}$ & $\begin{array}{l}1.00 \\
5.16(0.86-30.75)\end{array}$ \\
\hline
\end{tabular}

$\star p<0.05$.

†Dichotomised in office clerks with an absence rate $\leqslant 2.4 \%$ and office clerks with an absence rate $>2.4 \%$

$\neq$ Dichotomised in office clerks with an absence rate due to respiratory symptoms $\leqslant 1.4 \%$ and office clerks with an absence rate due to respiratory symptoms $>1.4 \%$. 
Table 5 Influence of age, smoking habit, and respiratory complaints on absence prevalence, absence prevalence due to respiratory symptoms, absence rate, and absence rate due to respiratory symptoms among blue collar workers

\begin{tabular}{|c|c|c|c|c|c|}
\hline Risk factor & $\begin{array}{l}\text { No of } \\
\text { workers }\end{array}$ & $\begin{array}{l}\text { Absence prevalence } \\
\text { OR }(95 \% C I)\end{array}$ & $\begin{array}{l}\text { Absence prevalence due to } \\
\text { respiratory symptoms } \\
\text { OR }(95 \%-C I)\end{array}$ & $\begin{array}{l}\text { Absence rate† } \\
\text { OR }(95 \%-C I)\end{array}$ & $\begin{array}{l}\text { Absence rate } \ddagger \text { due to } \\
\text { respiratory symptoms } \\
\text { OR }(95 \%-C I)\end{array}$ \\
\hline \multicolumn{6}{|l|}{ Age (y): } \\
\hline $\begin{array}{l}21-35 \\
36-50 \\
51-65\end{array}$ & $\begin{array}{r}87 \\
134 \\
82\end{array}$ & $\begin{array}{l}1.00 \\
0.81(0.38-1.69) \\
0.70(0.31-1.59)\end{array}$ & $\begin{array}{l}1.00 \\
0.69(0.31-1.51) \\
0.68(0.28-1.65)\end{array}$ & $\begin{array}{l}1.00 \\
1.25(0 \cdot 66-2 \cdot 36) \\
1.04(0.51-2 \cdot 13)\end{array}$ & $\begin{array}{l}1.00 \\
0.64(0 \cdot 10-4 \cdot 18) \\
1.89(0 \cdot 34-10 \cdot 64)\end{array}$ \\
\hline \multicolumn{6}{|l|}{ Smoking habit: } \\
\hline Non-smoker & 56 & 1.00 & 1.00 & 1.00 & 1.00 \\
\hline Ex-smoker & 109 & $1 \cdot 22(0.55-2 \cdot 70)$ & $1 \cdot 22(0 \cdot 46-3 \cdot 24)$ & $0.76(0.36-1.62)$ & $1.62(0 \cdot 17-15 \cdot 79)$ \\
\hline Smoker & 138 & $1.64(0.73-3.67)$ & $0.97(0.37-2.55)$ & $0.99(0.48-2.04)$ & $0.96(0.10-9.47)$ \\
\hline \multicolumn{6}{|l|}{ Respiratory complaints: } \\
\hline No symptoms & 241 & $1 \cdot 00$ & $1 \cdot 00$ & 1.00 & 1.00 \\
\hline$\geqslant 1$ symptom & 61 & $2 \cdot 64(0.98-7 \cdot 13)$ & $2 \cdot 42^{\star}(1 \cdot 14-5 \cdot 15)$ & $1.82(0.97-3.40)$ & $7 \cdot 10^{\star}(1 \cdot 76-29 \cdot 01)$ \\
\hline
\end{tabular}

$\star p<0.05$.

†ichotomised in blue collar workers with an absence rate $\leqslant 7.6 \%$ and blue collar workers with an absence rate $>7.6 \%$.

$\neq$ Dichotomised in blue collar workers with an absence rate due to respiratory symptoms $\leqslant 3 \cdot 1 \%$ and blue collar workers with an absence rate due to respiratory symptoms $>3.1 \%$.

risk factors on absence prevalence and absence rates among office clerks and blue collar workers. In the analyses presented, age showed no clear relation with various indices of sickness absence. The older office clerks were absent significantly less than the younger office clerks. This result is based on a small number of subjects, however. In both groups, smokers had a higher absence prevalence than non-smokers, but the differences were not statistically significant. Among blue collar workers smoking habits did not influence the absence prevalence and absence rate due to respiratory sickness. By contrast, office clerks who smoked showed decreased risks for absenteeism due to respiratory symptoms (prevalence and rate), but these findings were not statistically significant.

Respiratory complaints were significantly associated with sickness absence due to all causes and due to respiratory symptoms. Office clerks and blue collar workers with at least one respiratory complaint had ORs for absence prevalences and absence rates of 1.9 and $2 \cdot 6$, and $3 \cdot 4$ and $1 \cdot 8$, respectively. In general, when regarding absence due to respiratory symptoms, these associations were greatly increased. The corresponding ORs were 4.4 and $2 \cdot 4$, and 5.2 and $7 \cdot 1$, respectively. A consideration of only subjects taking medicine because of respiratory complaints, gave even stronger relation with sickness absence among blue collar workers. Among blue collar workers, the OR was $9 \cdot 3(95 \%$ CI 1.9-44.6) for subjects taking medicine because of their respiratory problems. In the subgroup of office clerks who sought medical care because of respiratory complaints the risk fell to $1 \cdot 9(95 \%$ CI $0 \cdot 2-22 \cdot 6)$.

Similar analyses with asthma like and chronic bronchitis like complaints showed no differences in absence prevalences and absence rates. One has to bear in mind that the number of subjects with asthma like or bronchitis like complaints was small.

\section{Discussion}

This cross sectional study was directed towards the occurrence of respiratory symptoms (chronic non-specific lung disease) and associated sickness absence among office clerks and blue collar workers of a large animal feed mill in the Netherlands. In both groups the prevalence of respiratory symptoms was about $20 \%$. Another Dutch study in the animal feed industry, with the same questionnaire, found comparable prevalences for respiratory symptoms among blue collar workers, office clerks, and external controls. ${ }^{13}$ A higher prevalence of respiratory symptoms among the blue collar workers was anticipated as they were exposed daily to organic dusts such as various grains. Organic dusts have been associated with different respiratory symptoms, including asthma ${ }^{1316}$ and chronic bronchitis. ${ }^{13} 1718$ The cross sectional approach in this study hampers any explanation for the modest prevalence among exposed workers, but evidence of a healthy worker effect among animal food workers and among grain elevator workers has been documented. ${ }^{13} 19$ The nonresponse may also have contributed to the moderate prevalence of respiratory complaints because the analysis of non-response showed that in both groups sickness absence was higher in non-responders than in the subjects participating in this study.

The well known role of smoking in the occurrence of respiratory complaints ${ }^{2021}$ was confirmed in the survey. Current smoking was strongly associated with respiratory complaints in both groups. Former smokers resembled lifetime non-smokers, which could be explained by the finding that former smokers, on average, had stopped smoking for almost 12 years. The relation between age and respiratory complaints was ambiguous. Among the office workers there was a declining trend, whereas the blue collar workers had an increased prevalence with age. Interpretation of these patterns is difficult. A possible cause could be that the respiratory symptoms included asthma and chronic obstructive pulmonary disease, which have different associations with age. Asthma expresses itself generally at an early age, whereas chronic bronchitis arises more often in older subjects. Separate analyses for asthma like complaints and for chronic bronchitis complaints, however, showed similar patterns in both groups. More likely, different mechanisms of a healthy worker selection play an important part. The proportion of office workers with respiratory 
complaints before entering the factory was substantially larger than the proportion among the blue collar workers. Because age and duration of employment were strongly correlated, duration of employment had similar patterns of association with respiratory complaints.

The information on the severity of the respiratory complaints indicated that for most subjects their complaints posed serious problems. Many had experienced several spells in the past six months, about $50 \%$ had symptoms for more than seven days, $37 \%$ sought medical care, and $30 \%$ reported taking medicine. The seriousness of the respiratory complaints was also reflected in the figures for sickness absence. Workers with respiratory symptoms were absent significantly more often due to respiratory symptoms than those without. Table 3 shows that prevalence, frequency, duration, and rate were increased among both the office clerks and the blue collar workers. These findings are in agreement with the few publications on this matter. ${ }^{9-11}$

Respiratory complaints were strongly associated with sickness absence due to respiratory symptoms. Sickness absence was characterised by absence rate which was dichotomised to distinguish subjects with high and those with low absence rates. Several cut off points were used and the general pattern remained fairly constant. Office clerks with respiratory complaints showed an OR of $5 \cdot 2$ (95\% CI 0.9-30.8) for absence due to respiratory symptoms compared with office clerks without these complaints. In the subgroup of office clerks who sought medical care because of respiratory complaints the risk fell to 1.9. Among the blue collar workers, subjects with respiratory complaints had a sevenfold risk of absence due to respiratory symptoms, which was increased to 9.3 for subjects taking medicine because of their respiratory problems. This finding indicates that subjects with (more severe) respiratory complaints can more easily survive performing administrative tasks, whereas they are at higher risk performing tasks with exposure to organic dust. In general, subjects with respiratory complaints were absent more due to influenza. This result stresses the well known fact that subjects with respiratory complaints are at risk for contracting influenza. ${ }^{22} 23$

Viewing sickness absence due to any cause, subjects with respiratory complaints were also absent from their work more often and longer because of health problems than subjects without respiratory symptoms, the ORs were $3.4(95 \%$ CI $1 \cdot 2-10 \cdot 1)$ and 1.8 (95\% CI $1 \cdot 0-3 \cdot 4)$ on absence rate due to any cause for office clerks and blue collar workers respectively. Among the office workers this was partly due to the high contribution of respiratory symptoms and influenza in the total sickness absence. For blue collar workers this contributed about $20 \%$. A detailed analysis indicated that workers with respiratory symptoms and exposed to animal feed products experienced a higher absence prevalence and absence rate due to musculoskeletal symp- toms than their colleagues without respiratory complaints. It may be postulated that subjects with respiratory complaints have decreased stamina and endurance, and, hence, are at risk of becoming ill more easily than subjects without respiratory problems. This hypothesis remains speculative in a cross sectional study.

Other risk factors for sickness absence studied were age and smoking habits. No apparent relation between age and absence due to respiratory symptoms was found. Current smoking did not affect absenteeism due to respiratory complaints. Former smokers, however, had a higher risk of sickness absence due to respiratory symptoms. This finding was not significant. Among office clerks current smoking was a risk factor for absence prevalence and absence rate due to any cause (OR 2.4 and OR $2 \cdot 6$, respectively), but these increased risks did not reach significance. In a large study among civil servants current smoking was found to be a risk factor for short time sickness absence (OR 1.5) and for long term sickness absence (OR 1.8). ${ }^{8}$

The current study has several limitations; most importantly its cross sectional design, the limited size of the population under study, the lack of differentiation between short term and long term sickness absence, and the grouping of sickness causes into broad categories. A cross sectional design is sensitive to selection processes in the workforce that are influenced by health state. These selection processes are likely to apply to chronic diseases such as respiratory disorders and, hence, the associations between respiratory symptoms and sickness absence may have been underestimated. ${ }^{1924}$ The limited size of the study population hampers detailed analyses and causes large $95 \%$ CIs, which prevents risk factors from reaching significance. This was particularly the case in the analysis of factors associated with respiratory absence. Therefore, it was not feasible to investigate the influence of important factors such as overall health, morbidity, and work requirements ${ }^{8}$ on the sickness absence due to respiratory diseases.

The limitations of using sickness absence data were obvious in this study. In general, four variables can be studied. In the population under study frequency, duration, and rate of sickness absence were all highly skewed and prompted us to dichotomise the data in the analysis. The choice was made to focus on absence rate rather than frequency and duration, because rate was most stable in the statistical analysis. The disadvantage of this approach is that an absentee often sick is regarded as similar to an absentee with a single spell of long sickness.

The sickness register introduced familiar problems, such as short absences without reported cause and broad categories of causes of sickness. For the current study it would have been of interest to retrieve specific diagnosis of sickness absence like asthma and chronic bronchitis. As most spells of absence were classified by the trained layman based upon the workers' complaints, retrieval of a 
specific diagnosis was not possible. The validity of the causes of absence was not studied. It was anticipated, however, that the validity and consistency of the sickness absence data were sufficiently high as the experienced layman and the occupational physician discussed the diagnosis of absent workers each week.

The finding that office clerks and blue collar workers with respiratory symptoms experienced a higher sickness absence due to this condition may offer additional opportunities to identify workers at risk for aggravation of their respiratory complaints. As sickness registers are instituted industrywide, sickness absence due to respiratory symptoms provides an instrument of continuous monitoring of an occupational population. Spells of respiratory sickness could be used to identify subjects at risk. The question whether these subjects will become permanently disabled cannot be answered with this study. In any case, secondary prevention is warranted in which respiratory complaints could be used as the focus, although the sensitivity and specificity are too limited to construct a particular screening programme.

In conclusion, the primary aim of this study was to determine risk factors for sickness absence due to respiratory symptoms. Workers with at least one respiratory complaint in the past 12 months showed a higher absence prevalence and absence rate for all causes of sickness than workers without respiratory complaints. These differences were more apparent when evaluating specifically sickness absence due to respiratory symptoms. Occupational exposure to animal feed products, such as grain dust, was of limited importance. Office clerks and blue collar workers showed similar patterns between respiratory symptoms and sickness absence. These associations indicate that workers with respiratory symptoms are at risk for temporary disability.

1 Woolcock AJ. Epidemiology of asthma. Am Rev Respir Dis 1992;146:1358-9.

2 Weiss KB, Gergen PJ, Wagener DK. Breathing better or wheezing worse? The changing epidemiology of asthma 14:491-513.

3 Howard P, Waterhouse JC. Mortality and its prevention in chronic obstructive pulmonary disease. European Respiratory Review 1992;2:9203-7.

4 Neuberger M, Kundi M, Friedl HP. Environmental factors in chronic obstructive pulmonary disease. European Respiratory Review 1992;2:9144-8.

5 Vermeire PA, Pride NB. A "splitting" look at chronic nonspecific lung disease (CNSLD): common features but diverse pathogenesis. Eur Respir $\mathcal{F}$ 1991;4:490-6.

6 Chan-Yeung M, Lam S. Occupational asthma. Am Rev Respir Dis 1986;133:688-703.

7 Becklacke MR. Occupational exposures: evidence for a causal association with chronic obstructive pulmonary disease. Am Rev Respir Dis 1989;140(suppl):85S-91S.

8 North F, Syme SL, Feeney A, Head J, Shipley MJ, Marmot MG. Explaining socioeconomic differences in sickness absence: the Whitehall II Study. BMF 1993; 306:361-6.

9 Gocke TM, McPherson P, Webb NC. Predicting respiratory absenteeism. Arch Environ Health 1965;10:332-7.

10 Jedrychowski $W$. Sickness absence caused by chest diseases in relation to smoking and chronic bronchitis symptoms. $\mathrm{Br} \mathcal{F}$ Ind $\mathrm{Med}$ 1976;33:243-8.

11 Comstock GW, Stone RW, Tonascia JA, Johnson DH. Respiratory survey findings as predictors of disability from respiratory diseases. Am Rev Respir Dis 1981;124: from respir.

12 Venables KM. Preventing occupational asthma. $\mathrm{Br} \mathcal{F}$ Ind Med 1992;49:817-9.

13 Smid T, Heederik D, Houba R, Quanjer PH. Dust- and endotoxin-related respiratory effects in the animal feed endotoxin-related respiratory effects in the anir
industry. Am Rev Respir Dis 1992;146:1474-9.

14 Medical Research Council Committee on the aetiology of chronic bronchitis. Instructions for the use of the questionnaire on respiratory symptoms. Dawlish, UK: Holman, 1966.

15 Minette A. Questionnaire of the European Community for coal and steel on respiratory symptoms. 1987-updating of the 1962 and 1967 questionnaires for studying chronic bronchitis and emphysema. Eur Respir f 1989; 2:165-77.

16 Chan-Yeung $M$, Schulzer $M$, Maclean L, Dorken $E$ Grzybouski S. Epidemiologic health survey of grain elevrzybouski S. Epidemiologic health survey of grain elevator workers in
$1980 ; 121: 329-38$.

17 Dosman JA, Graham BL, Hall D, Van Loon P, Blasin P, Froh F. Respiratory symptoms and pulmonary function in farmers. F Occup Med 1987;29:38-43.

18 Zuskin E, Schachter EN, Kanceljak B, Wilek TJ, Fein E. Organic dust disease of the airways. Int Arch Occup Environ Health 1993;65:135-40.

19 Broder I, Corey P, Davies G, Hutcheon M, Mintz S Inouye $T$, Hyland $R$. Longitudinal study of grain elevator and control workers with demonstration of the healthy worker effect. $\mathcal{F}$ Occup Med 1985;27:873-80.

20 Crofton J, Masironi R. Chronic airways disease: the smoking component. Chest 1989;96(suppl);349S-55S.

21 Sherman CB. The health consequences of cigarette smoking. Pulmonary diseases. Med Clin North Am 1992;76: ing. Pulmo

22 Cate TR. Clinical complications and consequences of influenza. $A m \mathcal{F} M e d$ 1987;82:15-9.

23 Connolly AM, Salmon RL, Lervy B, Williams DH. What are the complications of influenza and can they be prevented? $B M Y$ 1993;306:1452-4

24 Wen CP, Tsai SP, Gibson RL. Anatomy of the healthy worker effect: a critical review. F Occup Med 1983;25: 183-9. 